\title{
Subject Visit Type
}

National Cancer Institute

\section{Source}

National Cancer Institute. Subject Visit Type. NCI Thesaurus. Code C103165.

The kind of visit undertaken by the subject within a study, such as inpatient, outpatient, telephone, etc. 